The University of Maine

\title{
DigitalCommons@UMaine
}

Maine-Syracuse Longitudinal Papers

Maine-Syracuse Longitudinal Study

2008

\section{Relation Between Central Adiposity and Cognitive Function in the Maine-Syracuse Study: Attenuation by Physical Activity}

Gregory A. Dore

Merrill F. Elias

University of Maine - Main, mfelias@maine.edu

Michael A. Robbins

University of Maine - Main, robbins@maine.edu

Marc M. Budge

Penelope K. Elias

Follow this and additional works at: https://digitalcommons.library.umaine.edu/ longitudinal_papers

Part of the Cognitive Psychology Commons

\section{Repository Citation}

Dore, G. A., Elias, M. F., Robbins, M. A., Budge, M. M., \& Elias, P. K. (2008). Relationship between central adiposity and cognitive function in the Maine-Syracuse Study: Attenuation by physical activity. Annals of Behavioral Medicine, 35, 341-350.

This Article is brought to you for free and open access by DigitalCommons@UMaine. It has been accepted for inclusion in Maine-Syracuse Longitudinal Papers by an authorized administrator of DigitalCommons@UMaine. For more information, please contact um.library.technical.services@maine.edu. 


\title{
Relation Between Central Adiposity and Cognitive Function in the Maine-Syracuse Study: Attenuation by Physical Activity
}

\author{
Gregory A. Dore, B.A. • Merrill F. Elias, Ph.D., M.P.H. • \\ Michael A. Robbins, Ph.D. • \\ Marc M. Budge, M.B.B.S., B.Med.Sc. • \\ Penelope K. Elias, Ph.D.
}

Published online: 27 June 2008

(C) The Society of Behavioral Medicine 2008

\begin{abstract}
Background Previous studies have demonstrated a relationship between central adiposity and cognitive function. However, only some of these studies have adjusted for cardiovascular risk factors and cardiovascular disease, and none have also adjusted for physical activity level.

Purpose The purpose of the study was to examine the association between anthropometric measures of central adiposity (waist circumference and waist/hip ratio) and cognitive functioning with adjustment for cardiovascular disease risk factors and physical activity.

Methods Participants were 917 stroke- and dementia-free community-dwelling adults (59\% women) in the MaineSyracuse Study. The design was cross-sectional. Outcome measures included tests from the Wechsler Adult Intelligence Scale, the Halstead-Reitan Neuropsychological Battery, the Wechsler Memory Scale Revised, and the Mini-Mental State Examination.
\end{abstract}

G. A. Dore $(\bowtie) \cdot$ M. F. Elias · M. A. Robbins · P. K. Elias Department of Psychology,

University of Maine,

5742 Little Hall,

Orono, ME 04469-5742, USA

e-mail: gregory.dore@maine.edu

M. F. Elias - M. A. Robbins

Graduate School of Biomedical Sciences, University of Maine, 5742 Little Hall,

Orono, ME 04469-5742, USA

M. M. Budge

Department of Geriatric Medicine,

Australian National University Medical School,

Canberra, Australia
Results Waist circumference and waist/hip ratio were inversely related to multiple cognitive domains with adjustment for age, education, gender, and number of prior exams. For example, a $20-\mathrm{cm}$ increment in waist circumference was associated with a $0.14 \mathrm{SD}$ decrement in the Global Composite score. These relations were attenuated with adjustment for cardiovascular disease risk factors. However, with further adjustment for physical activity level, only waist circumference remained significantly associated with performance on the Similarities test.

Conclusions Waist circumference and waist/hip ratio are inversely related to cognitive function. Measures of central adiposity predict cognitive function independently of associated cardiovascular risk factors and events; however, the association between central adiposity and cognitive function is attenuated, to a large extent, by adjustment for physical activity level. Physical activity is an important covariate in studies relating measures of central adiposity to cognition.

Keywords Waist circumference - Waist/hip ratio · Adiposity $\cdot$ Cognitive function $\cdot$ Physical activity . Cardiovascular risk

\section{Introduction}

Obesity is a risk factor for cardiovascular disease (CVD), all-cause mortality [1], and morbidity [2, 3] and plays a central role in the metabolic syndrome [4]. In previous studies, a negative relationship between body mass index (BMI) and cognitive function [5-7] has been reported, but a measure of central adiposity was not employed. Central 
adiposity measures (i.e., waist circumference (WC) or waist/hip ratio (WHR)) provide more information than BMI concerning the distribution of body fat. Adipose tissue accumulated in the hip region may have a protective effect regarding cardiovascular disease and risk factors [8], and waist circumference has been shown to be a better predictor of all-cause mortality [9, 10], CVD mortality [11], and risk of CVD events [12] than BMI.

Recently, studies have been undertaken to relate measures of central adiposity to cognitive performance. An interactive effect of central adiposity and high blood pressure has been reported [13, 14], such that an inverse relationship between waist circumference or waist/hip ratio and cognitive function was observed in hypertensive, but not normotensive, individuals. Wolf et al. [14] adjusted only for age, education, and gender, whereas Waldstein and Katzel [13] adjusted for age, education, gender, multiple demographic and CVD risk factors, and components of the metabolic syndrome.

Physical activity level and cardiorespiratory fitness have received relatively little attention as possible confounders of the relation between central adiposity measures and cognitive performance. These variables are important predictors of cognitive function [15-17]. Indeed, improved cognitive test performance has been observed following exercise training [18]. Physical activity levels are also associated with decreased risk of mortality [19] and chronic disease, including diabetes mellitus [20]. Thus, in the present study, in addition to adjusting relations between adiposity and cognitive performance for CVD risk factors and events, we adjusted for physical activity level.

Our hypotheses were as follows: (1) measures of central adiposity, waist circumference and waist/hip ratio, will be inversely related to multiple domains of cognitive function; (2) the association between measures of central adiposity and cognitive performance will be sustained, though modestly attenuated, when adjusted for CVD factors and CVD events; (3) positive associations between physical activity level and cognitive performance will be observed; (4) statistically adjusting for physical activity will result in a major attenuation of relations between central adiposity and cognitive performance.

\section{Method}

\section{Participants}

The sample was provided by the Maine-Syracuse Longitudinal Study [MSLS; 21, 22]. This community-based study, initiated in 1975, involves a time-lagged sample of five cohorts defined by time of entry into the study (19752000). The MSLS provides data on cognitive functioning and blood pressure, CVD, CVD risk factors (CVD-RF), stroke, and prescription drugs, based on medical examination, an in-depth diagnostic interview, and hospital and physician records. The data from the current study are taken from the sixth study examination (2001-2006), as indices of central adiposity and some important CVD risk factors were first obtained at this exam.

Beginning with a sample size of 965 , participants were excluded for the following reasons: stroke $(n=33)$, dementia $(n=8)$, active dialysis treatment $(n=5)$, chronic alcohol abuse $(n=1)$, and not fluent in the English language $(n=1)$. The clinical diagnosis of dementia was determined by a panel consisting of one neurologist-geriatrician and three neuropsychologists using the National Institute of Neurological and Communicative Diseases and Stroke-Alzheimer's Disease and Related Disorders Association criteria and cognition and medical interview data from the MaineSyracuse Study [23]. Prevalent stroke, defined as a focal neurological deficit of acute onset persisting more than $24 \mathrm{~h}$, was based on self-report and record review (with permission) and confirmed by hospitalization, treatment for stroke, or both.

We certify that all applicable institutional and governmental regulations concerning the ethical use of human volunteers were followed during this research. The University of Maine Institutional Review Board approved the investigation and informed consent for data collection, and medical record review was obtained for all participants.

\section{Procedure}

Participants completed questionnaires, including the Center for Epidemiologic Studies depression scale [CES-D; 24] and the Nurses' Health Study Activity Questionnaire [17], within a week prior to the study. They were admitted to the study center following a fast from midnight. A blood sample was drawn by a licensed phlebotomist, and a light breakfast, including decaffeinated coffee or tea, was served and followed by a physical examination, including a detailed medical history and neuropsychological testing. Waist circumference and hip circumference (in centimeters) were both measured using a non-extendable measuring tape. Waist circumference was measured at the level of the iliac crest, and hip circumference was measured at the largest extension of the buttocks. All measurements were taken with the subject wearing light clothing.

\section{Neuropsychological Battery}

The tests included in the neuropsychological battery, with a brief description of what each test measures and references to the origins of the tests and details of test administration, may be found in Table 1. The battery, designed to measure 
Table 1 Descriptions of the cognitive tests with factor loadings from the factor analysis confirmed in this study

\begin{tabular}{|c|c|c|}
\hline Test composite/tests included in the composite & Latent cognitive variable tested & Reference \\
\hline Global composite ( $z$ score) & Global composite of cognitive performance & \\
\hline \multicolumn{3}{|l|}{ Verbal memory } \\
\hline Logical memory-immediate recall ${ }^{\mathrm{a}}$ & Immediate memory, verbal & 36 \\
\hline Logical memory-delayed recall $^{\mathrm{a}}$ & Delayed memory, verbal & 36 \\
\hline Hopkins verbal learning test & Verbal learning and memory & 31 \\
\hline \multicolumn{3}{|l|}{ Visual-spatial organization } \\
\hline Visual reproductions-immediate recall ${ }^{\mathrm{a}}$ & $\begin{array}{l}\text { Immediate recall, visual memory, and visual-spatial } \\
\text { problem solving }\end{array}$ & 36 \\
\hline Visual reproductions-delayed recall ${ }^{\mathrm{a}}$ & $\begin{array}{l}\text { Delayed recall, visual memory and visual-spatial } \\
\text { problem solving }\end{array}$ & 36 \\
\hline Matrix reasoning $^{\mathrm{b}}$ & Abstract reasoning and pattern recognition & 37 \\
\hline Block design ${ }^{c}$ & Visual-spatial perception, organization and construction & 30 \\
\hline Object assembly ${ }^{\mathrm{c}}$ & Speed of visual-spatial organization & 30 \\
\hline Hooper visual organization test & $\begin{array}{l}\text { Visual-spatial organization; some demands on } \\
\text { executive function }\end{array}$ & 32,33 \\
\hline \multicolumn{3}{|l|}{ Scanning and tracking } \\
\hline Trail making $\mathrm{A}^{\mathrm{d}}$ & Visual scanning and tracking & 35 \\
\hline Trail making $\mathrm{B}^{\mathrm{d}}$ & Complex visual scanning, tracking and executive function & 35 \\
\hline Digit symbol substitution $^{\mathrm{c}}$ & Psychomotor performance & 30 \\
\hline Symbol search ${ }^{\mathrm{b}}$ & Visual processing speed & 37 \\
\hline \multicolumn{3}{|l|}{ Working memory } \\
\hline Digit span forward ${ }^{\mathrm{c}}$ & Attention and concentration & 30 \\
\hline Digit span backward ${ }^{\mathrm{c}}$ & Attention, concentration, and working memory & 30 \\
\hline Letter-number sequence ${ }^{\mathrm{b}}$ & Working memory & 37 \\
\hline Controlled oral word associations & Verbal fluency and executive functioning & 34 \\
\hline Similarities $^{\mathrm{c}}$ & Abstract reasoning & 30 \\
\hline Mini-Mental State Examination (MMSE) ${ }^{\mathrm{e}}$ & Global cognitive screening & 26 \\
\hline
\end{tabular}

${ }^{\mathrm{a}}$ Origin WMS-R

${ }^{\mathrm{b}}$ Origin WAIS III

${ }^{\mathrm{c}}$ Origin WAIS

${ }^{\mathrm{d}}$ Origin Halstead-Reitan NP Test Battery

${ }^{\mathrm{e}}$ Excluded from the factor analysis

a wide range of cognitive abilities [25], has been employed in studies relating hypertension and other cardiovascular risk factors to cognitive performance [21, 22].

We employed the Mini-Mental State Examination [MMSE; 26] and the Maine-Syracuse neuropsychological test battery [21, 22, 27-29], which included the Similarities test from the Wechsler Adult Intelligence Scale [WAIS; 30] and four composite scores resulting from a previous factor analysis [21] which identified four relatively independent cognitive domains: Visual-Spatial Memory and Organization, Scanning and Tracking, Verbal Episodic Memory, and Working Memory. Each composite score was constructed by summing standard scores for the Hopkins Verbal Learning Test [31], the Hooper Visual Organization Test [32, 33], the Controlled Oral Word Associations Test [34], and multiple individual tests taken from the HalsteadReitan Neuropsychological Test Battery [35], the Wechsler Memory Scale-Revised [36], the original WAIS [30], and the WAIS III [37].
Test scores were transformed to $z$-scores. This linear transformation results in a mean of zero and a standard deviation (SD) of 1.00 for each test and represents an expression of regression coefficients for the cognitive measures in terms of SD units. Factor analytic methods and tests making up the composites are fully described in a recent paper [28]. These previously identified composites were confirmed in the present study via replication of the factor analysis. The Similarities subtest from the WAIS, a measure of abstract reasoning [25, 30], loaded on multiple factors and was treated as a separate measure. In addition to composite scores based on factor analysis, a Global Composite score was calculated by averaging the $z$-scores for all individual tests (excluding the MMSE). The Global Composite and MMSE were considered separate measures of global performance. All the tests used in the composite scores are widely used in research and clinical practice and have been described elsewhere in detail $[25,26,30,34-37]$. 
Independent Variables and Covariates

The independent variables were WC (in centimeters) and WHR. Covariates employed in the regression models (described below) were age (years), education (years), gender, number of prior examinations, smoking (cigarettes per week), the ratio of triglycerides $(\mathrm{mmol} / \mathrm{l})$ to high density lipoprotein cholesterol (mmol/l; TG/HDL-C), prevalent CVD, high sensitivity C-reactive protein (CRP; mg/l), systolic blood pressure (SBP; mm Hg), depressed mood, glucose $(\mathrm{mg} / \mathrm{dl})$, and physical activity (PA; metabolic equivalent task (MET)-hours per week).

Education level was obtained through self-report and ranged from 4 to 20 years. Gender was coded as 0 for men and 1 for women. Although the current study is crosssectional, as noted previously, participants were recruited into the parent (longitudinal) study at various waves. Consequently, the number of prior exams for each subject (range from 1 to 5) was used as a covariate scored from 1 to 5. Smoking was measured by self-reported number of cigarettes smoked per week. Glucose, TG and HDL-C were assessed from serum using standard colorimetric methods at a commercial laboratory. Analyses (not presented) were also performed with glucose and TG/HDL-C replaced with prevalent diabetes and a total cholesterol to HDL-C ratio, respectively. The pattern of results was the same. Prevalent CVD was a dichotomous variable (yes $=1$, no $=0$ ); this variable included a history of any of the following: coronary artery disease, myocardial infarction, congestive heart failure, transient ischemic attack, or angina pectoris. These variables were assessed by self report, followed by a medical history review (with permission). High sensitivity CRP was assessed from plasma using a latex particle enhanced turbidimetric immunoassay technique [38]. Five blood pressure measurements were obtained with subjects in each of the sitting, recumbent, and standing positions and averaged for SBP and diastolic blood pressure (DBP). Depressed mood was defined as a score greater than or equal to 16 on the CES-D because the distribution of scores is skewed and we were interested in adjusting for a clinically accepted level for depressed mood [39]. When analyses (results not presented) were also done with CES-D as a continuous variable, no changes in the pattern of significant results were observed.

Average hours per week spent on leisure time physical activity was measured using the physical activity questionnaire from the Nurses' Health Study [17]. This questionnaire is reported to be a valid measure of long-term physical activity levels [40]. Participants were asked, "during the past year, what was your average time per week spent at each of the following recreational activities?" Activities included walking or hiking outdoors; jogging (slower than $10 \mathrm{~min} /$ mile); running (10 min/mile or faster); bicycling; calisthen- ics, aerobics or exercise machine use; tennis, squash, or racquetball; lap swimming; and other aerobic recreation. The range of possible values for each activity was 0 to $11 \mathrm{~h}$. In addition, participants were asked, "What is your usual walking pace outdoors?" Possible responses to this question were: easy, casual (less than $2 \mathrm{mph}$ ); normal, average (2-2.9 $\mathrm{mph}$ ); brisk pace (3-3.9 mph); very brisk or striding (4 mph or faster); and unable to walk. A MET value for each activity was assigned using the compendium of physical activities developed by Ainsworth et al. [41] and values used previously by the Nurses' Health Study investigators [17, 40]. The MET values for each activity were multiplied by the number of hours spent at each activity to obtain MET-hours per week for each activity. The total MET-hours per week spent at leisure time physical activity was obtained by summing the MET-hours for the individual activities.

\section{Statistical Methods}

Pearson product moment coefficients $(r)$ were calculated among WC, WHR, PA, and the cognitive outcome variables. Distributions for hs-CRP and physical activity were skewed and were normalized with a natural log transformation. In separate sets of multivariate regression analyses, relations between these independent variables and cognition were adjusted in a sequential manner for the following covariate sets: (1) a Basic covariate set including age, education, gender, and number of prior exams; (2) a risk factor and CVD covariate set (Basic $+\mathrm{RF}+\mathrm{CVD}$ ) including the Basic covariate set and smoking, alcohol consumption, TG/HDL-C, prevalent CVD, SBP, depressed mood, glucose, and CRP; (3) a Physical Activity covariate set including the Basic $+\mathrm{RF}+\mathrm{CVD}$ covariates and physical activity. Two tailed tests of significance $(\alpha=.05)$ were employed.

\section{Results}

\section{Sample Characteristics}

After exclusions, the sample consisted of 917 individuals (59\% women), aged 23-98 years. The demographics and health characteristics of the sample are described in Table 2. Mean values for waist circumference are comparable to overall national averages and averages for men and women separately [42].

\section{Preliminary Analyses}

\section{Zero-order Correlations}

Correlations among the central adiposity variables, physical activity, and cognitive outcome variables are given in 
Table 2 Demographic information and health characteristics $(n=917)$

\begin{tabular}{|c|c|c|}
\hline Variable & $\begin{array}{l}\text { Mean }(\mathrm{SD}) \\
\text { or percent }\end{array}$ & Range \\
\hline Age, mean (SD), years & $62.0(12.8)$ & $23-98$ \\
\hline Education, mean (SD), years & $14.6(2.7)$ & $4-20$ \\
\hline Women, No. $(\%)$ & $541(59.0)$ & \\
\hline $\begin{array}{l}\text { Number of prior exams, } \\
\text { mean (SD) }\end{array}$ & $1.5(1.1)$ & $1-5$ \\
\hline \multicolumn{3}{|l|}{ Waist circumference $(\mathrm{cm})$, mean $(\mathrm{SD})$} \\
\hline Overall & $95.5(15.1)$ & $61-199$ \\
\hline Men & $102.3(13.2)$ & $74-186$ \\
\hline Women & $90.7(14.5)$ & $61-199$ \\
\hline \multicolumn{3}{|l|}{ Waist/hip ratio, mean (SD) } \\
\hline Overall & $0.880(.089)$ & $0.646-1.202$ \\
\hline Men & $0.945(.061)$ & $0.766-1.121$ \\
\hline Women & $0.834(.077)$ & $0.646-1.202$ \\
\hline \multicolumn{3}{|l|}{ Alcohol, oz/week, mean (SD) } \\
\hline Drinkers only & $3.0(3.6)$ & $0.4-33.6$ \\
\hline Full sample & $1.5(3.0)$ & $0-33.6$ \\
\hline \multicolumn{3}{|l|}{ Cigarettes per week, mean (SD) } \\
\hline Smokers only & $100.3(74.2)$ & $1-441$ \\
\hline Full sample & $9.4(37.0)$ & $0-441$ \\
\hline $\begin{array}{l}\text { Triglycerides (TG), } \\
\text { mmol/1, mean (SD) }\end{array}$ & $1.6(1.3)$ & $0.3-11.3$ \\
\hline HDL-C, mmol/1, mean (SD) & $1.4(.4)$ & $0.4-2.6$ \\
\hline TG/HDL ratio, mean (SD) & $1.4(1.4)$ & $0.1-15.6$ \\
\hline Glucose, mg/dl, mean (SD) & $99.4(29.0)$ & $47-372$ \\
\hline C-reactive protein, mg/l, mean (SD) & $4.1(4.6)$ & $0.4-46.5$ \\
\hline $\begin{array}{l}\text { Systolic blood pressure, } \\
\mathrm{mm} \mathrm{Hg} \text {, mean (SD) }\end{array}$ & $131.5(21.5)$ & $82-226$ \\
\hline $\begin{array}{l}\text { Diastolic blood pressure, } \\
\mathrm{mm} \mathrm{Hg} \text {, mean (SD) }\end{array}$ & $70.8(10.0)$ & $45-128$ \\
\hline $\begin{array}{l}\text { Physical activity, MET-hours/week, } \\
\text { mean (SD) }\end{array}$ & $20.5(27.2)$ & $0.0-216.5$ \\
\hline Elevated waist circumference ${ }^{\mathrm{a}}$, No. (\%) & $469(48.2)$ & \\
\hline Depressed mood, No. (\%) & $94(10.3)$ & \\
\hline Smoker, No. (\%) & $86(9.4)$ & \\
\hline CVD, No. (\%) & $141(15.4)$ & \\
\hline Hypertensive, No. (\%) & $576(62.8)$ & \\
\hline Diabetic, No. (\%) & $117(12.8)$ & \\
\hline
\end{tabular}

${ }^{a}$ Based on gender-specific cut points from Grundy et al. (4)

Table 3. Waist circumference, waist/hip ratio, and physical activity levels were significantly related to all cognitive outcome variables. These relations were similar in strength for all predictor variables.

\section{Test of Interactions}

Previous investigations have observed interactions between central adiposity measures and blood pressure or hypertension [13, 14]. All tests of interactions between central adiposity measures and blood pressure (or hypertension) were nonsignificant for all cognitive outcome measures:
$\mathrm{WC} \times \mathrm{SBP}(p \mathrm{~s}>.11), \mathrm{WHR} \times \mathrm{SBP}(p \mathrm{~s}>.52), \mathrm{WC} \times \mathrm{DBP}$ $(p \mathrm{~s}>.28)$, WHR $\times$ DBP $(p \mathrm{~s}>.59), \mathrm{WC} \times$ Hypertension $(p \mathrm{~s}>.23)$, WHR $\times$ Hypertension $(p s>.27)$. When the gender-specific waist/hip ratio cut-points (men, high $\geq 0.99$, women, high $\geq 0.84$ ) used by Wolf et al. [14] were employed in a reanalysis, a significant WHR $\times$ Hypertension interaction was observed for Similarities $(p<.01)$. Participants with a high WHR and hypertension performed more poorly than participants with a high WHR without hypertension. The categorical WHR $\times$ Hypertension interaction was nonsignificant for all other cognitive outcome measures $(p s>10)$. There were no significant interactions of the predictors (WC or WHR) with age, gender, or physical activity $(p \mathrm{~s}>.05)$.

\section{Basic Model}

Regression coefficients ( $\beta$ ), their respective 95\% confidence intervals $(95 \% \mathrm{CI})$, and $p$-values for multiple regression analyses relating WC to cognitive performance are reported in Table 4 . Because $1 \mathrm{~cm}$ of $\mathrm{WC}$ is a small unit, regression coefficients were multiplied by 10 in order to report cognitive performance levels in relation to $10 \mathrm{~cm}$ increments in WC. Table 4 describes the magnitude of the associations between $10 \mathrm{~cm}$ increases in $\mathrm{WC}$ and cognitive performance expressed in units of SD ( $z$ scores). For example, a $10-\mathrm{cm}$ increment in waist circumference in the Basic model was associated with a 0.07 SD decrement in the Global Composite. Stated differently, a person with a waist circumference $1.5 \mathrm{SD}$ above the mean would perform at a level $0.10 \mathrm{SD}$ lower than a person with the mean waist circumference. In the Basic Model, WC showed inverse associations with all cognitive outcome measures, with the

Table 3 Zero-order correlations between waist circumference $(\mathrm{cm})$, waist/hip ratio, physical activity (ln MET $\cdot h \cdot w^{-1} \mathrm{k}^{-1}$ ), and cognitive measures

\begin{tabular}{lrlll}
\hline Physical activity or central adiposity measure & & \\
Cognitive & \multicolumn{2}{l}{$\begin{array}{l}\text { Waist } \\
\text { circumference }\end{array}$} & $\begin{array}{l}\text { Waist/hip } \\
\text { ratio }\end{array}$ & $\begin{array}{l}\text { Physical } \\
\text { activity }\end{array}$ \\
\hline Global composite & $r$ & $-.13^{* * *}$ & $-.21^{* * *}$ & $.19^{* * *}$ \\
Verbal memory & $r$ & $-.09^{* *}$ & $-.16^{* * *}$ & $.11^{* * *}$ \\
Visual-spatial organization & $r$ & $-.08^{*}$ & $-.15^{* * *}$ & $.17^{* * *}$ \\
Scanning and tracking & $r$ & $-.13^{* * *}$ & $-.22^{* * *}$ & $.18^{* * *}$ \\
Working memory & $r$ & $-.11^{* * *}$ & $-.15^{* * *}$ & $.13^{* * *}$ \\
Similarities & $r$ & $-.15^{* * *}$ & $-.08^{*}$ & $.18^{* * *}$ \\
MMSE & $r$ & $-.10^{* *}$ & $-.09^{*}$ & $.09^{* *}$ \\
Waist circumference & $r$ & - & $.70^{* * *}$ & $-.19^{* * *}$ \\
Waist/hip ratio & $r$ & $.70^{* * *}$ & - & $-.12^{* * *}$ \\
\hline
\end{tabular}

$r$ Zero-order correlation

$* p<.05, * * p<.01, * * * p<.001$ 
Table 4 Regression coefficients $(\beta)$ and $95 \%$ confidence intervals $(95 \% \mathrm{CI})$ expressing the relationship between waist circumference (10 cm increments) and cognitive outcome variables ( $z$-scores)

\begin{tabular}{|c|c|c|c|c|}
\hline \multirow[b]{2}{*}{ Cognitive outcome } & & \multicolumn{3}{|l|}{ Covariate set } \\
\hline & & Basic $^{\mathrm{a}}$ & Basic $+\mathrm{RF}^{\mathrm{b}}+\mathrm{CVD}$ & Basic $+\mathrm{RF}+\mathrm{CVD}+\mathrm{PA}^{\mathrm{c}}$ \\
\hline Global composite & $\begin{array}{l}\beta \\
95 \% \mathrm{CI}\end{array}$ & $\begin{array}{l}-0.0655 * * * \\
(-0.1036,-0.0274)\end{array}$ & $\begin{array}{l}-0.0543 * \\
(-0.0975,-0.0110)\end{array}$ & $\begin{array}{l}-0.0405 \\
(-0.0849,0.0039)\end{array}$ \\
\hline Verbal memory & $\begin{array}{l}\beta \\
95 \% \mathrm{CI}\end{array}$ & $\begin{array}{l}-0.0162 \\
(-0.0589,0.0264)\end{array}$ & $\begin{array}{l}-0.0045 \\
(-0.0526,0.0436)\end{array}$ & $\begin{array}{l}0.0016 \\
(-0.0477,0.0509)\end{array}$ \\
\hline Visual-spatial organization & $\begin{array}{l}\beta \\
95 \% \mathrm{CI}\end{array}$ & $\begin{array}{l}-0.0504 * \\
(-0.0899,-0.0109)\end{array}$ & $\begin{array}{l}-0.0405 \\
(-0.0849,0.0040)\end{array}$ & $\begin{array}{l}-0.0276 \\
(-0.0732,0.0180)\end{array}$ \\
\hline Scanning and tracking & $\begin{array}{l}\beta \\
95 \% \mathrm{CI}\end{array}$ & $\begin{array}{l}-0.0534 * * \\
(-0.0905,-0.0164)\end{array}$ & $\begin{array}{l}-0.0487 * \\
(-0.0910,-0.0065)\end{array}$ & $\begin{array}{l}-0.0349 \\
(-0.0782,0.0084)\end{array}$ \\
\hline Working memory & $\begin{array}{l}\beta \\
95 \% \mathrm{CI}\end{array}$ & $\begin{array}{l}-0.0541^{*} \\
(-0.0988,-0.0095)\end{array}$ & $\begin{array}{l}-0.0407 \\
(-0.0911,0.0097)\end{array}$ & $\begin{array}{l}-0.0282 \\
(-0.0799,0.0236)\end{array}$ \\
\hline Similarities & $\begin{array}{l}\beta \\
95 \% \mathrm{CI}\end{array}$ & $\begin{array}{l}-0.0791 * * * \\
(-0.1207,-0.0374)\end{array}$ & $\begin{array}{l}-0.0682 * * \\
(-0.1155,-0.0209)\end{array}$ & $\begin{array}{l}-0.0615^{*} \\
(-0.1100,-0.0130)\end{array}$ \\
\hline MMSE & $\begin{array}{l}\beta \\
95 \% \mathrm{CI}\end{array}$ & $\begin{array}{l}-0.0437 * \\
(-0.0873,-0.0000)\end{array}$ & $\begin{array}{l}-0.0186 \\
(-0.0669,0.0296)\end{array}$ & $\begin{array}{l}-0.0188 \\
(-0.0684,0.0308)\end{array}$ \\
\hline
\end{tabular}

${ }^{*} p<.05, * * p<.01, * * * p<.001$

${ }^{a}$ Basic covariate set $=$ age, education, gender, number of prior exams

${ }^{\mathrm{b}}$ Basic $+\mathrm{RF}+\mathrm{CVD}$ covariate set = age, education, gender, number of prior exams, smoking, alcohol consumption, triglycerides/high density lipoprotein cholesterol ratio, prevalent cardiovascular disease, systolic blood pressure, depressed mood, glucose, high sensitivity Creactive protein

${ }^{\mathrm{c}}$ Basic $+\mathrm{RF}+\mathrm{CVD}+\mathrm{PA}$ covariate set $=$ age, education, gender, number of prior exams, smoking, alcohol consumption, triglycerides/high density lipoprotein cholesterol ratio, prevalent cardiovascular disease, systolic blood pressure, depressed mood, glucose, high sensitivity Creactive protein, physical activity

exception of the Verbal Memory Composite. Similar relations were observed between WHR and cognitive performance (Table 5); however, waist/hip ratio was not related to performance on the Similarities test or the MMSE.

Basic + RF + CVD Model

When the Basic + RF + CVD covariate set was employed, results for $\mathrm{WC}$ were attenuated, but significant associations remained for the Global Composite, the Scanning and Tracking Composite, and Similarities (Table 4). In a slightly different pattern of results, WHR was related to performance on the Global Composite, the Visual-Spatial Organization Composite, and the Working Memory Composite (Table 5).

\section{Relation Between Physical Activity and Cognition}

Results for the association between physical activity and cognitive outcome variables are shown in Table 6. In the Basic + RF + CVD covariate set with WC, physical activity was related to all cognitive outcome measures except the MMSE and the Verbal Memory $(p>.06)$ and Working Memory composites $(p>.07)$. When WHR was substituted for WC in this model, the pattern of results was the same.

\section{Basic + RF + CVD + PA Model}

The addition of physical activity to the Basic + RF + CVD model resulted in attenuation of the magnitude of the regression coefficients for waist circumference (Table 4). In fact, the only significant relationship observed between WC and cognitive function with Physical Activity added to the model was for Similarities. With adjustment for the Basic + $\mathrm{RF}+\mathrm{CVD}+\mathrm{PA}$ covariate set, WHR was not significantly related to any cognitive outcomes (Table 5).

\section{Discussion}

Measures of central adiposity were related to multiple domains of cognitive functioning. With statistical control for age, education, gender, and number of prior exams, waist circumference and waist/hip ratio were inversely related to the Global, Visual-Spatial Organization, Scanning and Tracking, and Working Memory composites. Waist circumference was also inversely related to the Similarities test and the MMSE. With adjustment for components of the metabolic syndrome and related CVD risk factors, the associations between $\mathrm{WC}$ and cognitive function were slightly attenuated, but remained significant for the Global Composite, Scanning and Tracking Com- 
Table 5 Regression coefficients $(\beta)$ and $95 \%$ confidence intervals (95\% CI) expressing the relationship between waist/hip ratio and cognitive outcome variables ( $z$-scores)

\begin{tabular}{|c|c|c|c|c|}
\hline \multirow[b]{2}{*}{ Cognitive outcome } & & \multicolumn{3}{|l|}{ Covariate set } \\
\hline & & Basic $^{\mathrm{a}}$ & Basic $+\mathrm{RF}^{\mathrm{b}}+\mathrm{CVD}$ & $\mathrm{Basic}+\mathrm{RF}+\mathrm{CVD}+\mathrm{PA}^{\mathrm{c}}$ \\
\hline \multirow[t]{2}{*}{ Global composite } & $\beta$ & $-1.2697 * * *$ & $-0.8187^{*}$ & -0.5237 \\
\hline & $95 \% \mathrm{CI}$ & $(-2.0292,-0.5101)$ & $(-1.6325,-0.0048)$ & $(-1.3587,0.3041)$ \\
\hline \multirow[t]{2}{*}{ Verbal memory } & $\beta$ & -0.2527 & 0.1832 & 0.3189 \\
\hline & $95 \% \mathrm{CI}$ & $(-1.1106,0.6052)$ & $(-0.7321,1.0985)$ & $(-0.6161,1.2539)$ \\
\hline \multirow[t]{2}{*}{ Visual-spatial organization } & $\beta$ & $-1.3625 * * *$ & $-0.9094 *$ & -0.6840 \\
\hline & $95 \% \mathrm{CI}$ & $(-2.1525,-0.5725)$ & $(-1.7515,-0.0673)$ & $(-1.5451,0.1771)$ \\
\hline \multirow[t]{2}{*}{ Scanning and tracking } & $\beta$ & $-0.7461 *$ & -0.3856 & -0.0522 \\
\hline & $95 \% \mathrm{CI}$ & $(-1.4858,-0.0064)$ & $(-1.1809,0.4097)$ & $(-0.8627,0.7584)$ \\
\hline \multirow[t]{2}{*}{ Working memory } & $\beta$ & $-1.3172 * *$ & $-0.9938 *$ & -0.7432 \\
\hline & $95 \% \mathrm{CI}$ & $(-2.2134,-0.4210)$ & $(-1.9521,-0.0355)$ & $(-1.7245,0.2382)$ \\
\hline \multirow[t]{2}{*}{ Similarities } & $\beta$ & -0.6602 & -0.3586 & -0.1192 \\
\hline & $95 \% \mathrm{CI}$ & $(-1.5037,0.1834)$ & $(-1.2628,0.5455)$ & $(1.0425,0.8041)$ \\
\hline \multirow[t]{2}{*}{ MMSE } & $\beta$ & -0.7237 & -0.2117 & -0.1760 \\
\hline & $95 \% \mathrm{CI}$ & $(-1.5977,0.1504)$ & $(-1.1259,0.7026)$ & $(-1.1130,0.7610)$ \\
\hline
\end{tabular}

${ }^{*} p<.05, * * p<.01, * * * p<.001$

${ }^{a}$ Basic covariate set $=$ age, education, gender, number of prior exams

${ }^{\mathrm{b}}$ Basic $+\mathrm{RF}+\mathrm{CVD}$ covariate set = age, education, gender, number of prior exams, smoking, alcohol consumption, triglycerides/high density lipoprotein cholesterol ratio, prevalent cardiovascular disease, systolic blood pressure, depressed mood, glucose, high sensitivity Creactive protein

${ }^{\mathrm{c}}$ Basic $+\mathrm{RF}+\mathrm{CVD}+\mathrm{PA}$ covariate set $=$ age, education, gender, number of prior exams, smoking, alcohol consumption, triglycerides/high density lipoprotein cholesterol ratio, prevalent cardiovascular disease, systolic blood pressure, depressed mood, glucose, high sensitivity Creactive protein, physical activity

posite, and Similarities. The associations between WHR and cognitive function were also attenuated in this model, but significant associations remained for the Global, Visual-Spatial Organization, and Working Memory composites. Generally, these findings are similar to those of previous studies investigating the relationship between central adiposity and cognition $[13,14]$, BMI and cognition [7], and BMI-defined obesity and cognition [5].
Previous studies investigating the relationship between central adiposity and cognitive function have found that measures of central adiposity are inversely related to cognitive function, but only for hypertensive individuals $[13,14]$. In the study by Waldstein and Katzel [13], this interaction was found only for tests that are not included in the MaineSyracuse battery and was not significant for tests which are included in the present battery, suggesting that this effect
Table 6 Regression coefficients $(\beta)$ and $95 \%$ confidence intervals $(95 \% \mathrm{CI})$ expressing the relationship between physical activity (ln MET'hours'week ${ }^{-1}$ ) and cognitive outcome variables $(z$-scores $)$ in the Basic $+\mathrm{RF}+$ CVD covariate set

Basic + RF + CVD covariate set $=[$ obesity covariate $]$, age, education, gender, number of prior exams, smoking, alcohol consumption, triglycerides/high density lipoprotein cholesterol ratio, prevalent cardiovascular disease, systolic blood pressure, depressed mood, glucose, high sensitivity C-reactive protein. $* p<.05, * * p<.01, * * * p<.001$

\begin{tabular}{clll}
\hline & & Obesity covariate & \\
\cline { 2 - 3 } Cognitive outcome & & Waist \\
& & circumference & Waist/hip ratio \\
\hline Global composite & $\beta$ & $0.0577^{* *}$ & \\
Verbal memory & $95 \% \mathrm{CI}$ & $(0.0147,0.1007)$ & $0.0601^{* *}$ \\
& $\beta$ & 0.0439 & $(0.0171,0.1030)$ \\
Visual-spatial & $95 \% \mathrm{CI}$ & $(-0.0042,0.0920)$ & 0.0447 \\
organization & $\beta$ & $0.0493^{*}$ & $(-0.0034,0.0929)$ \\
Scanning and & $95 \% \mathrm{CI}$ & $(0.0049,0.0937)$ & $0.0482^{*}$ \\
tracking & $\beta$ & $0.0654 * *$ & $(0.0038,0.0925)$ \\
Working memory & $\beta$ & $(0.0236,0.1072)$ & $0.0706^{* * *}$ \\
Similarities & $95 \% \mathrm{CI}$ & 0.0455 & $(0.0288,0.1124)$ \\
& $\beta$ & $(-0.0050,0.0960)$ & 0.0437 \\
MMSE & $95 \% \mathrm{CI}$ & $0.0529 *$ & $(-0.0068,0.0942)$ \\
& $\beta$ & $(0.0056,0.1002)$ & $0.0615^{*}$ \\
& $95 \% \mathrm{CI}$ & -0.0108 & $(0.0140,0.1090)$ \\
\hline
\end{tabular}


may be specific to cognitive domains not measured in the current study. Wolf et al. [14] found that elevated waist/hip ratio predicted lowered cognitive function only in the presence of hypertension, but this study did not include adjustment for cardiovascular risk factors. Therefore, it is uncertain whether this lowered performance is due to a synergistic effect of elevated central adiposity and hypertension or to other closely related cardiovascular risk factors, such as diabetes or increased systemic inflammation.

Previous studies have shown self-reported physical activity [43] and objective measures of cardiorespiratory fitness [44] to be robust predictors of cognitive function across multiple domains [16], with the largest effects observed for measures of executive function. However, few studies investigating the relationship between obesity and cognitive function have included a measure of physical activity or physical fitness $[7,13]$. Thus, one major purpose of our study was to determine if physical activity level modified the relationship between measures of central adiposity and cognitive performance. Physical activity was positively and significantly related to cognitive function, even after adjustment for CVD risk factors, CVD, and central adiposity. With adjustment for physical activity, however, waist circumference was related only to the Similarities test, and waist/hip ratio was not significantly related to any outcome measures. One possibility is that this finding was due to chance because it represents one statistically significant finding within the context of multiple analyses with adjustment for physical activity.

Although cardiovascular disease events and risk factors may partially mediate associations between central adiposity and cognition, our study and others [13] have shown that relations between central adiposity and cognition are sustained regardless of statistical adjustment for cardiovascular risk factors and events. Clearly no study to date has adjusted for all possible risk factors and cardiovascular events. On the other hand, there are other mechanisms that might possibly explain the relation between central adiposity and cognition.

Central adiposity has been linked to an increase in prevalence of white matter hyperintensities in the brain [45] and to emerging risk factors for cardiovascular disease such as elevated systemic inflammation [46]. It is not highly likely that systemic inflammation provides an explanation in the present study because, unlike previous studies, we adjusted for C-reactive protein as a possible confounder.

There are several possible mechanisms which may explain the relationship between physical activity levels and cognitive function, and why adjustment for physical activity attenuates results for adiposity variables. One possibility is that this phenomenon is simply due to collinearity between central adiposity and activity level. However, correlational analyses do not support this interpretation.
It is not unreasonable to hypothesize that increased levels of physical activity result in weight loss, thereby decreasing the amount of adipose tissue. Although one of the likely consequences of physical activity is weight loss, beneficial effects of physical activity on cardiovascular disease risk factors are also observed in the absence of profound weight loss [47]. The current study suggests that the association between physical activity and cognitive function may be only partially mediated through adipose tissue. However, there are several possible alternative explanations for the association between physical activity and cognitive function. Physical activity has been shown to increase serotonin and dopamine levels [48], as well as increasing insulin sensitivity [49]. These compounds have all been shown to be positively correlated with cognition [50-52]. Physical activity also has beneficial effects on the vascular system, including reduction of atherosclerotic plaque accumulation [53], decreased blood pressure [54], and subsequent reduction of cardiovascular disease risk [55]. Investigations have also found increased neurogenesis as a result of exercise in the rat $[56,57]$.

The cross-sectional design is a limitation of the current study. Participants with higher levels of cognitive function may be more likely to engage in health-promoting behaviors. Another limitation of the current study was the fact that physical activity levels were measured by selfreport, which may have been affected by erroneous recall. Also, retrospectively estimating physical activity levels requires cognitive skills assessed by some of the outcome measures. However, physical activity and cognition have been shown to be positively related cross-sectionally [15], prospectively [58], and longitudinally [17]. Thus, the fact that physical activity and cognition are positively correlated in the present study is unlikely to be simply the result of erroneous recall. Further, a greater extent of erroneous recall among poorer cognitive performers would increase the variability in the physical activity measure. This increased variability would result in an underestimation of the magnitude of the association between physical activity and cognitive function. Lastly, this sample was composed of relatively high-functioning subjects, so recall of past physical activity levels and responding to physical activity questions probably make minimal demands on their intellect. However, it is important to consider these possibilities in future studies using longitudinal assessments of cognition and physical activity.

Strengths of the current study include a relatively large community-based sample, objective data on risk factors for CVD and CVD events, and a validated measure of activity level.

While CVD risk factors have been adjusted in previous studies of obesity and waist/hip ratio, to our knowledge, no studies have simultaneously adjusted for activity level. In 
summary, measures of central adiposity were related to multiple measures of cognitive function. This association was significantly attenuated with statistical adjustment for leisure-time physical activity levels. Thus it is important to include a measure of physical activity or cardiorespiratory fitness in addition to CVD risk factors when investigating the relationship between obesity and cognitive function. Aside from central adiposity, our study reinforces the recent recommendations for minimal levels of physical activity [59]. Further studies are needed to investigate the vascular, endocrine, and neurochemical mechanisms explaining the association between physical activity and cognitive function, and the extent to which these mechanisms are independent of obesity.

Acknowledgements This study was supported in part by Research Grants HL67358 and HL81290 from the National Heart, Lung, and Blood Institute and Research Grant AG03055 from the National Institute on Aging. The content is solely the responsibility of the authors and does not necessarily represent the official views of the National Heart, Lung, and Blood Institute, the National Institute on Aging, or the National Institutes of Health. The authors wish to thank Suzanne Brennan for assistance in data collection, and Amanda Goodell and Anna Sweeney for assistance in copyediting.

\section{References}

1. Calle EE, Thun MJ, Petrelli JM, Rodriguez C, Heath CW Jr. Body-mass index and mortality in a prospective cohort of US adults. $N$ Engl J Med. 1999; 341: 1097-1105.

2. Cabrera MA, Gebara OC, Diament J, Nussbacher A, Rosano G, Wajngarten M. Metabolic syndrome, abdominal obesity, and cardiovascular risk in elderly women. Int $J$ Cardiol. 2007; 114: 224-229.

3. Jonsson S, Hedblad B, Engstrom G, Nilsson P, Berglund G, Janzon L. Influence of obesity on cardiovascular risk. Twenty-three-year follow-up of 22,025 men from an urban Swedish population. Int $J$ Obes Relat Metab Disord. 2002; 26: 1046-1053.

4. Grundy SM, Brewer HB Jr., Cleeman JI, Smith SC Jr., Lenfant C. Definition of metabolic syndrome: Report of the National Heart, Lung, and Blood Institute/American Heart Association conference on scientific issues related to definition. Circulation. 2004; 109: 433-438.

5. Elias MF, Elias PK, Sullivan LM, Wolf PA, D'Agostino RB. Lower cognitive function in the presence of obesity and hypertension: The Framingham heart study. Int $J$ Obes Relat Metab Disord. 2003; 27: 260-268.

6. Gunstad J, Paul RH, Cohen RA, Tate DF, Gordon E. Obesity is associated with memory deficits in young and middle-aged adults. Eat Weight Disord. 2006; 11: e15-e19.

7. Cournot M, Marquie JC, Ansiau D, et al. Relation between body mass index and cognitive function in healthy middle-aged men and women. Neurology. 2006; 67: 1208-1214.

8. Dixon JB, Strauss BJ, Laurie C, O'Brien PE. Smaller hip circumference is associated with dyslipidemia and the metabolic syndrome in obese women. Obes Surg. 2007; 17: 770-777.

9. Bigaard J, Frederiksen K, Tjonneland A, et al. Waist circumference and body composition in relation to all-cause mortality in middle-aged men and women. Int J Obes. 2005; 29: 778-784.
10. Simpson JA, MacInnis RJ, Peeters A, Hopper JL, Giles GG, English DR. A comparison of adiposity measures as predictors of all-cause mortality: The Melbourne Collaborative Cohort Study. Obesity. 2007; 15: 994-1003.

11. Baik I, Ascherio A, Rimm EB, et al. Adiposity and mortality in men. Am J Epidemiol. 2000; 152: 264-271.

12. Yusuf S, Hawken S, Ounpuu S, et al. Obesity and the risk of myocardial infarction in 27,000 participants from 52 countries: A case-control study. Lancet. 2005; 366: 1640-1649.

13. Waldstein SR, Katzel LI. Interactive relations of central versus total obesity and blood pressure to cognitive function. Int J Obes. 2006; 30: 201-207.

14. Wolf PA, Beiser A, Elias MF, Au R, Vasan RS, Seshadri S. Relation of obesity to cognitive function: Importance of central obesity and synergistic influence of concomitant hypertension. The Framingham Heart Study. Curr Alzheimer Res. 2007; 4: 111-116.

15. Hillman CH, Motl RW, Pontifex MB, et al. Physical activity and cognitive function in a cross-section of younger and older community-dwelling individuals. Health Psychol. 2006; 25: 678-687.

16. Kramer AF, Colcombe SJ, McAuley E, Scalf PE, Erickson KI. Fitness, aging and neurocognitive function. Neurobiol Aging. 2005; 26Suppl 1: 124-127.

17. Weuve J, Kang JH, Manson JE, Breteler MM, Ware JH, Grodstein F. Physical activity, including walking, and cognitive function in older women. JAMA. 2004; 292: 1454-1461.

18. Colcombe S, Kramer AF. Fitness effects on the cognitive function of older adults: A meta-analytic study. Psychol Sci. 2003; 14: $125-130$

19. Hu G, Tuomilehto J, Silventoinen K, Barengo NC, Peltonen M, Jousilahti P. The effects of physical activity and body mass index on cardiovascular, cancer and all-cause mortality among 47212 middle-aged Finnish men and women. Int J Obes. 2005; 29: 894902.

20. Telford RD. Low physical activity and obesity: Causes of chronic disease or simply predictors? Med Sci Sports Exerc. 2007; 39: $1233-1240$.

21. Elias MF, Robbins MA, Budge MM, et al. Homocysteine, folate, and vitamins B6 and B12 blood levels in relation to cognitive performance: The Maine-Syracuse study. Psychosom Med. 2006; 68: 547-554.

22. Robbins MA, Elias MF, Elias PK, Budge MM. Blood pressure and cognitive function in an African-American and a CaucasianAmerican sample: The Maine-Syracuse Study. Psychosom Med. 2005; 67: 707-714.

23. McKhann G, Drachman D, Folstein M, Katzman R, Price D, Stadlan EM. Clinical diagnosis of Alzheimer's disease: Report of the NINCDS-ADRDA Work Group under the auspices of Department of Health and Human Services Task Force on Alzheimer's Disease. Neurology. 1984; 34: 939-944.

24. Radloff LS. The CES-D Scale: A self-report depression scale for research in the general population. Appl Psychol Meas. 1977; 1: 385-401.

25. Lezak MD, Howieson DB, Loring DW. Neuropsychological assessment. 4th ed. New York: Oxford University Press; 2004.

26. Folstein MF, Folstein SE, McHugh PR. "Mini-mental state". A practical method for grading the cognitive state of patients for the clinician. J Psychiatr Res. 1975; 12: 189-198.

27. Dore GA, Elias MF, Robbins MA, Elias PK, Brennan SL. Cognitive performance and age: Norms from the Maine-Syracuse Study. Exp Aging Res. 2007; 33: 205-271.

28. Elias MF, Robbins MA, Budge MM, et al. Homocysteine and cognitive performance: Modification by the ApoE genotype. Neurosci Lett. 2008; 430: 64-69.

29. Robbins MA, Elias MF, Budge MM, Brennan SL, Elias PK. Homocysteine, type 2 diabetes mellitus, and cognitive perfor- 
mance: The Maine-Syracuse Study. Clin Chem Lab Med. 2005; 43: 1101-1106.

30. Wechsler D. Manual for the Wechsler Adult Intelligence Scale. New York: Psychological; 1955.

31. Brandt J. The hopkins verbal learning test: Development of a new memory test with six equivalent forms. Clin Neuropsychol. 1991; 5: $125-142$.

32. Boyd JL. A validity study of the Hooper Visual Organization Test. J Consult Clin Psychol. 1981; 49: 15-19.

33. Johnstone B, Wilhelm KL. The construct validity of the Hooper Visual Organization Test. Assessment. 1997; 4: 243-248.

34. Benton AL, Hamsher K de S. Multilingual Aphasia Examination. Iowa: AJA; 1989.

35. Reitan RM, Wolfson D. The Halstead-Reitan Neuropsychological Test battery: Theory and clinical interpretation. Tucson: Neuropsychology; 1993.

36. Wechsler D. Manual for the Wechsler Memory Scale-Revised. New York: Psychological; 1987.

37. Wechsler D. Wechsler Adult Intelligence Scale. 3rd ed. San Antonio: Psychological; 1997.

38. Ridker PM. High-sensitivity C-reactive protein: Potential adjunct for global risk assessment in the primary prevention of cardiovascular disease. Circulation. 2001; 103: 1813-1818.

39. Whooley MA, Kiefe CI, Chesney MA, Markovitz JH, Matthews K, Hulley SB. Depressive symptoms, unemployment, and loss of income: The CARDIA Study. Arch Intern Med. 2002; 162: 2614 2620.

40. Wolf AM, Hunter DJ, Colditz GA, et al. Reproducibility and validity of a self-administered physical activity questionnaire. Int J Epidemiol. 1994; 23: 991-999.

41. Ainsworth BE, Haskell WL, Leon AS, et al. Compendium of physical activities: Classification of energy costs of human physical activities. Med Sci Sports Exerc. 1993; 25: 71-80.

42. Ford ES, Mokdad AH, Giles WH. Trends in waist circumference among U.S. adults. Obes Res. 2003; 11: 1223-1231.

43. Singh-Manoux A, Hillsdon M, Brunner E, Marmot M. Effects of physical activity on cognitive functioning in middle age: Evidence from the Whitehall II prospective cohort study. Am J Public Health. 2005; 95: 2252-2258.

44. Deary IJ, Whalley LJ, Batty GD, Starr JM. Physical fitness and lifetime cognitive change. Neurology. 2006; 67: 1195-1200.

45. Jagust W, Harvey D, Mungas D, Haan M. Central obesity and the aging brain. Arch Neurol. 2005; 62: 1545-1548.
46. Kershaw EE, Flier JS. Adipose tissue as an endocrine organ. $J$ Clin Endocrinol Metab. 2004; 89: 2548-2556.

47. Slentz CA, Houmard JA, Kraus WE. Modest exercise prevents the progressive disease associated with physical inactivity. Exerc Sport Sci Rev. 2007; 35: 18-23.

48. Meeusen R. Exercise and the brain: Insight in new therapeutic modalities. Ann Transplant. 2005; 10: 49-51.

49. Gill JM. Physical activity, cardiorespiratory fitness and insulin resistance: A short update. Curr Opin Lipidol. 2007; 18: 47-52.

50. Mitchell RL, Phillips LH. The psychological, neurochemical and functional neuroanatomical mediators of the effects of positive and negative mood on executive functions. Neuropsychologia. 2007; 45: 617-629.

51. van der Meulen JA, Joosten RN, de Bruin JP, Feenstra MG. Dopamine and noradrenaline efflux in the medial prefrontal cortex during serial reversals and extinction of instrumental goal-directed behavior. Cereb Cortex. 2007; 17: 1444-1453.

52. Di Bonito P, Di Fraia L, Di Gennaro L, et al. Impact of impaired fasting glucose and other metabolic factors on cognitive function in elderly people. Nutr Metab Cardiovasc Dis. 2007; 17: 203 208.

53. Wilund KR. Is the anti-inflammatory effect of regular exercise responsible for reduced cardiovascular disease? Clin Sci. 2007; 112: 543-555.

54. Steffen PR, Sherwood A, Gullette EC, Georgiades A, Hinderliter A, Blumenthal JA. Effects of exercise and weight loss on blood pressure during daily life. Med Sci Sports Exerc. 2001; 33: 16351640 .

55. Adamu B, Sani MU, Abdu A. Physical exercise and health: A review. Niger J Med. 2006; 15: 190-196.

56. van Praag H, Christie BR, Sejnowski TJ, Gage FH. Running enhances neurogenesis, learning, and long-term potentiation in mice. Proc Natl Acad Sci U S A. 1999; 96: 13427-13431.

57. van Praag H, Kempermann G, Gage FH. Running increases cell proliferation and neurogenesis in the adult mouse dentate gyrus. Nat Neurosci. 1999; 2: 266-270.

58. Yaffe K, Barnes D, Nevitt M, Lui LY, Covinsky K. A prospective study of physical activity and cognitive decline in elderly women: Women who walk. Arch Intern Med. 2001; 161: 1703-1708.

59. Haskell WL, Lee I, Pate RR, et al. Physical activity and public health: Updated recommendation for adults from the American College of Sports Medicine and the American Heart Association. Med Sci Sports Exerc. 2007; 39: 1423-1434. 